\title{
Recycling of Polymers - An Opportunity or a Threat to the Economy?
}

\author{
Alfira Khaertdinova ${ }^{1, *}$, Dilbar Sultanova ${ }^{1}$, Dinara Iskhakova $^{1}$, and Albert Karimov ${ }^{2}$ \\ ${ }^{1}$ Kazan National Research Technological University, Department of innovation in chemical technology, 420015, Kazan, Russia \\ ${ }^{2}$ Ministry of Industry and Trade of Republic of Tatarstan, 420111, Kazan, Russia
}

\begin{abstract}
Products of the polymer industry today are everywhere. They have penetrated both our daily life and the development of high-tech industries. In the current reality, new technologies are developing at a rapid pace and pose new challenges to the polymer industry. However, with the growth of production and consumption of plastics, the problem of recycling waste from the polymer industry has gradually become more acute. This article analyzes the production of plastics, their utilization and assesses the prospects for further development of the industry in developed countries. Separately, the issues of solving these problems in Europe are studied as a model of managing the recycling process and possible borrowing the experience for the Russian economy.
\end{abstract}

\section{Introduction}

In the early 19th century, chemical scientists in the United States, Germany, France, Italy, and Russia began working and tried to replace strategic natural polymers as wood, rubber with synthetic replacements. Active industrial production began only at the beginning of the 20th century even though the prerequisites for this were available earlier. For mass production of polymers, consumers are primarily needed. These could be industrial countries with a high proportion of urban populations. According to statistics, the share of the urban population in the countries was not uniform. It follows that the development of industry is also not equivalent. For example, Fig. 1 shows that in 1913 the urban population prevailed in England, Norway, Germany, and the United States.

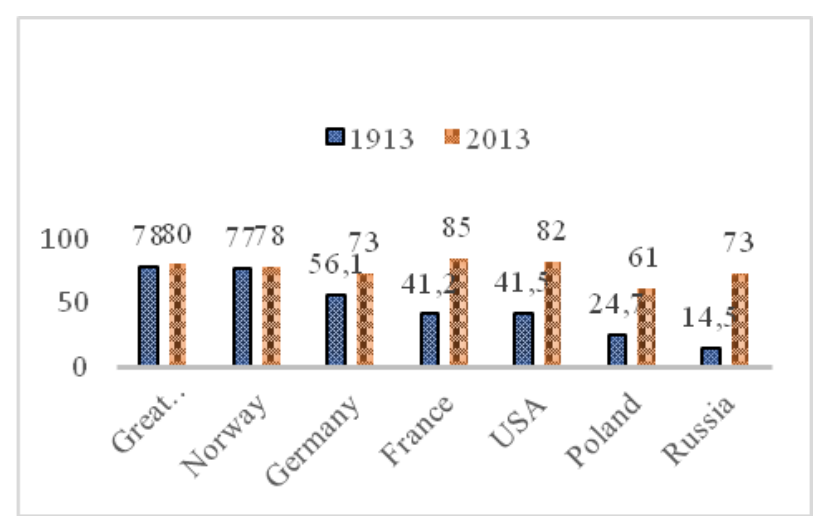

Fig. 1. Urban population structure in different countries in 1913 and $2013(\%)$.

Accordingly, the share of industry in these countries prevailed, which created the driving force for these developments from the chemical industry. In 1913, the United States (35.8\%), Germany (15.7\%), and Great Britain (14.0\%) were the leaders in world industrial production. Russia's output was only $5.3 \%$. [1] A hundred years later, Germany and Great Britain lost their position to China (19.8\%) and USA (15.3\%).

This uneven distribution of the industrial structure led to the fact that chemical production began to develop more rapidly in the United States and Europe, and then in the East. For example, in Europe, in the early 20-30s of the last century, industrial use of polymers obtained by polymerization began. Thus, attempts were made to replace expensive natural raw materials with cheaper and affordable synthetic analogues. By the end of the 30s, production of nitrocellulose plastics had also begun in Russia (or rather in the former USSR). Since the middle of the last century, there has been a steady trend of constant growth in the global plastics market. However, by the beginning of the 21 st century, there was an awareness of the threat posed to the environment by polymers that are not subject to subsequent recycling or disposal.

Object of research: waste management of the polymer industry in developed countries and the European Union

Subject of research: key factors that determine the effectiveness of waste management in EU countries.

Hypothesis: the effectiveness of waste management is determined by a number of factors, including not only scientific and production indicators, but also socioeconomic ones.

\footnotetext{
* Corresponding author: alfira gks@mail.ru
} 


\section{Literature review}

About 6.5 billion tons of plastic and rubber waste is generated annually around the world. [2] Plastics are inexpensive, lightweight, easy to assemble. However, the problem of recycling these materials is acute. [3 - 7] Some polymers can only be destroyed by burning at extremely high temperatures $[5,8]$.

In the United States, less than $10 \%$ of polymeric waste was recycled while, $15 \%$ was incinerated and $75 \%$ went to landfill, half of which was exported to China. However, since March 12018 [9] China has drastically reduced waste imports, resulting in an accumulation of a pile of plastic waste in the United States. This led the public to pay attention to the problem of recycling and improving recycling methods. There are currently 633 businesses in America that can clean and sort waste. Reality has confirmed that they cannot cope with the available volumes. Against this background, many companies suspend collection, while others increase their value. Many plastics manufacturers and processors, universities, foundations, international organizations are looking for more sustainable waste management solutions. Americans have never perceived the burning process as an environmentally friendly method [10] even though it converts waste into energy. The opposition sharply criticized this dangerous method and opposed plans to build new incinerators in New York, Baltimore and Seattle [10].

Western Europe also stored its waste in China for many years. As practice has shown, the European waste management system is largely dependent on their export. As soon as the possibility of dumping waste in third world countries has decreased, the issue has moved from important to the most urgent. According to Science Daily, if polymer production and processing volumes remain at the same level, then by 2030 more than 110 million tons will accumulate in the world. plastic waste. Mostly they will be concentrated in Europe and the USA. [11]

The leader in waste processing is Germany, where $70 \%$ of the waste is recycled (the rest is burnt). Waste incineration is widespread in Europe and Southeast Asia. [10] However, modern burning is expensive. Not everyone is ready to build modern incinerators.

In January 2019, the European Commission introduced a polymer processing strategy, which suggests that by 2030 all polymer products should be collected and reused. At the same time, the sorting and processing facilities in Europe should increase fourfold and, thanks to this, 200 thousand jobs will be created. [11] In a circular economy, it is assumed that polymer products must be manufactured and assembled in such a way that they are easy to separate and recycle after use. [10]

In Russia, the volume of polymer recycling is only gaining momentum and is currently significantly behind the European countries by several times (in absolute terms). A high proportion (more than 50\%) of all waste is subject to disposal or incineration (Fig. 2). [12]

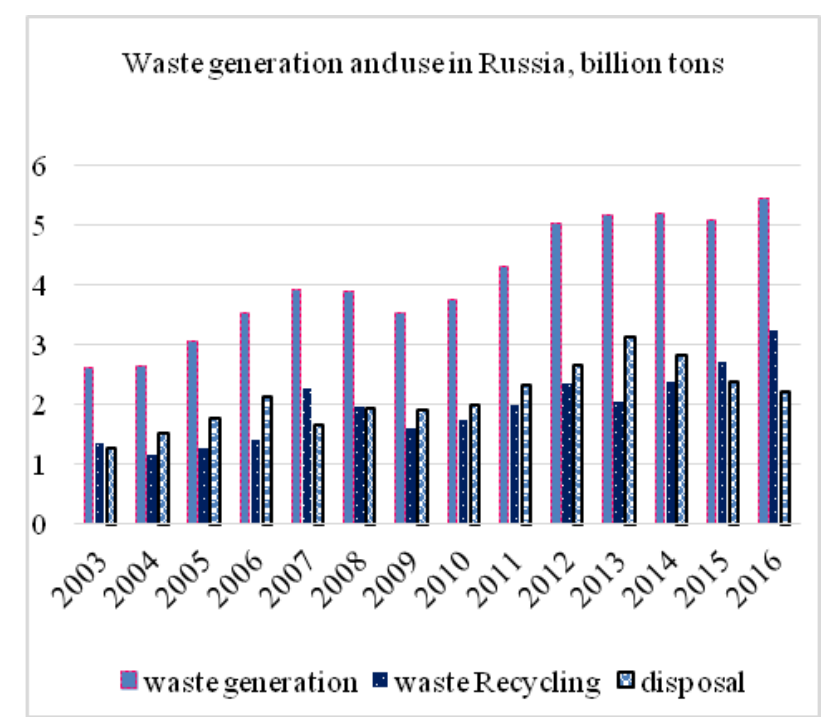

Fig. 2. Dynamics of waste generation and use in Russia.

The maximum percentage of polymer recycling is only a tenth. Therefore, the study of best practices remains one of the most important issues for Russian polymer waste processors. This makes it necessary to study the best practices of developed countries and implement them in Russia in order to reduce the rate of pollution of the planet.

\section{Results}

The growth of the polymer industry in the world is explained by its unambiguous importance for human life and society. The average annual growth rate of their production has continued to be significant for many decades. Of course, they cannot be compared with the end of the last century, but the indicators for the beginning of the $21^{\text {st }}$ century continue to be consistently high. Europe accounts for almost a quarter of all polymers produced in the world. In terms of demand for plastic products, Europe remains one of the most attractive markets in the world. The annual growth of production in the EU countries remains at the level of 23\% (Fig. 3). [13]

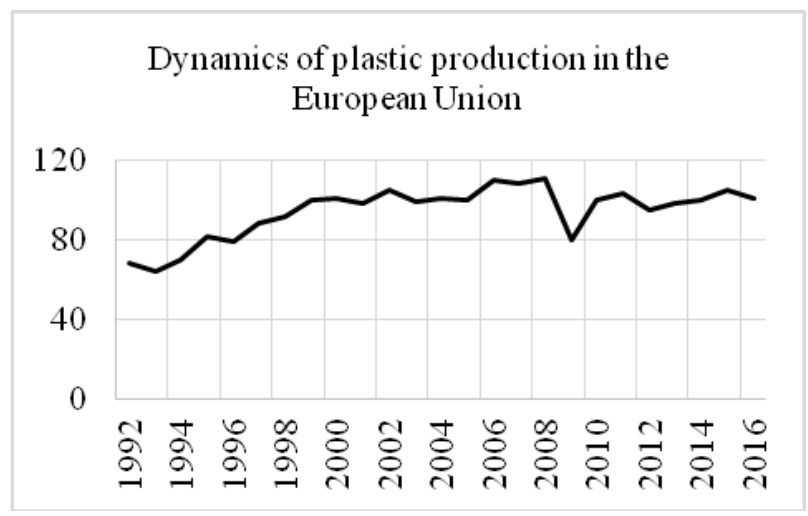

Fig. 3. Dynamics of plastic production in EU countries (in \% of the previous year). 
Only 2009, which was impacted by the global financial decline, was an exception to the positive trend (Fig. 4) [12].

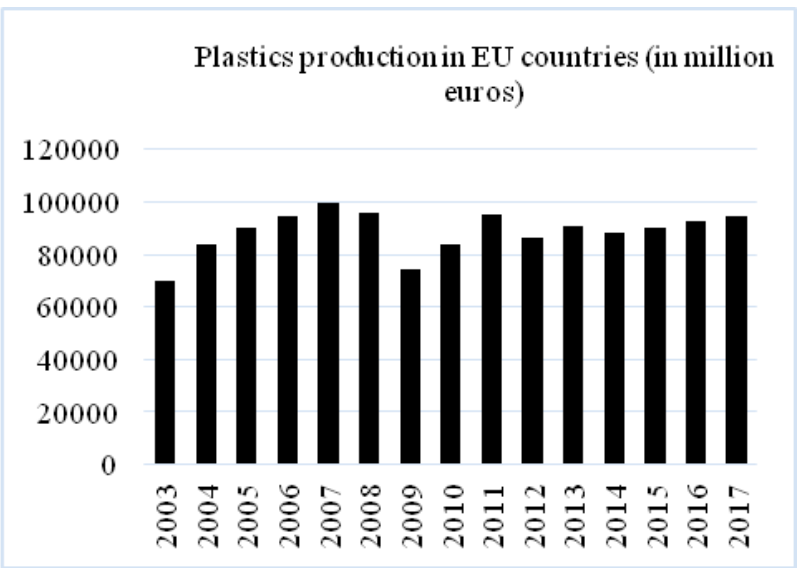

Fig. 4. Plastic Production in EU countries in millions of Euros.

The driving force of the industry is still the growth of the population in cities, and now in villages. This is primarily polymer building and packaging materials, automotive details.

In the Russian Federation, polymer production began to develop actively in the 60 s and 70 s of the last century. The beginning of the 90's in Russia were marked by a deep economic downturn, and the industry declined. However, the production of polymer materials quickly recovered and began to develop with steady positive growth. In the last decade, the average annual increase in the production of basic polymers in Russia, shown in table 1, was $6.1 \%$. [12] The total polymer capacity in Russia consists of basic polymers: polypropylene, polyethylene, polyvinyl chloride, pet film and fiber purpose.

Table 1. The rate of growth of production of basic polymers in Russia.

\begin{tabular}{|c|c|c|c|c|c|c|}
\hline & $\mathbf{2 0 1 3}$ & $\mathbf{2 0 1 4}$ & $\mathbf{2 0 1 5}$ & $\mathbf{2 0 1 6}$ & $\mathbf{2 0 1 7}$ & $\mathbf{2 0 1 8}$ \\
\hline $\begin{array}{c}\text { in \% by } \\
2010\end{array}$ & 125.0 & 127.6 & 143.8 & 151.5 & 154.7 & 161.0 \\
\hline $\begin{array}{c}\text { \% } \\
\text { previous } \\
\text { year }\end{array}$ & 117.3 & 102.1 & 112.7 & 105.4 & 102.1 & 104.1 \\
\hline
\end{tabular}

According to Fig. 5, you can see the total production and consumption of base polymers in Russia. Domestic production did not cover consumption until 2018, although production developed at a faster pace than consumption. [12]

The Russian economic situation in 2014-2015 was in an internal crisis (economic sanctions). Combined an the economic downturn, the polymer industry also sank. In general, the present production of base polymers is almost equal to the demand for them. It should be noted that «this convergence was influenced by the downward trend in demand for polyethylene film». [14] However, the Russian market is supported by imports. So, from 2013 to 2017, the average annual import of polymers was about 1.3 million tons at a total cost of almost $\$ 25$ million. After the ruble lost its position and the cost of imports increased, the volume of foreign purchases decreased. According to table 2, this dynamic can be easily traced.

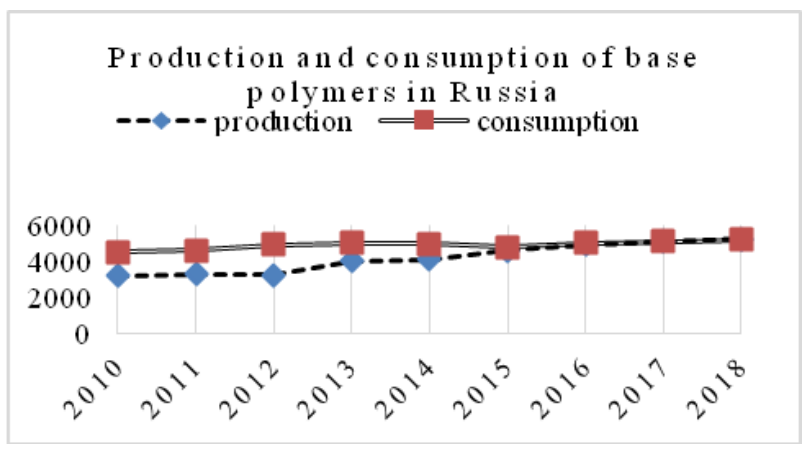

Fig. 5. Production and consumption of base polymers in Russia (thousand tons).

Table 2. Import of polymers to Russia, in millions USD

\begin{tabular}{|l|l|l|l|l|l|}
\hline & $\mathbf{2 0 1 3}$ & $\mathbf{2 0 1 4}$ & $\mathbf{2 0 1 5}$ & $\mathbf{2 0 1 6}$ & $\mathbf{2 0 1 7}$ \\
\hline Base polymer & 6161 & 5863 & 4079 & 3957 & 4597 \\
\hline
\end{tabular}

Such a huge production of plastic inevitably creates the problem that all countries of the world are facing the problem of recycling plastic waste. The accumulated amount of spent polymers is directly proportional to its production. From this point of view, it is important to analyze the recycling situation in different countries. The lack of a waste management policy courses to an absence of well-established system of accounting as a consequence and to complexity of the analysis of plastic consumption waste.

Polymers are poorly degradable materials. Many of them do not decompose and have a negative impact on the environment. It is often much cheaper for businesses to dispose of plastic in the form of landfill or incineration than to sort and reuse plastic due to lower costs. However, certain types of polymers are easily recyclable. The closed-cycle economy basis is the renewal of used resources. Its goal is to switch to wastefree production. Any garbage, including polymer, must be sorted and then taken out for processing. The remaining part that is not recyclable must be disposed of. Secondary raw materials are suitable for the production of many products: from bottles and low-pressure pipes to parts for vehicles.

For the Russian Federation, as we mentioned earlier, the problem of recycling of plastics is a relatively new issue. However, the world has accumulated good experience. The developed countries of the United States, Japan, China, as well as the countries of the old world - Germany, Austria, France and others have long been engaged in solving this problem and have achieved significant results.

In Japan, $60 \%$ of used plastic is converted into useful goods. In the United States, each state has its own way to solve this problem, but in general, more than $30 \%$ of used waste gets a second life. In European countries, plastic recycling issues are being successfully resolved, although in different ways for different regions. The leaders in this issue are Germany and Austria, where 
recycling of polymers reaches up to $70 \%$. In order to study the factors that determine the effectiveness of waste management in EU, we conducted a correlation analysis. As indicators, which were the basis for the analysis was considered: the overall percentage of recycling in the EU, the share of recycling, including glass recycling, paper and plastic and the percentage of recycled plastic in total waste. As a hypothesis, the following provisions were put forward:

- H1. The higher the country's GDP the better the waste management indicators;

- H2. The higher the country's investment in R\&D, the more efficient waste processing and better developed recycling processes for plastic and other products;

- H3. The higher the human capital index, the more efficient the process of separate garbage collection and waste recycling is;

- H4. The smaller the area per capita, the more concerned it is about the environment and the higher the growth rate of garbage processing.

The correlation analysis for the values of $27 \mathrm{EU}$ countries showed (table 3) stable links between waste processing and investment in $\mathrm{R} \& \mathrm{D}$. Thus, the correlation coefficient of the development of recycling including plastic, glass, metal, paper) with investments in $\mathrm{R} \& \mathrm{D}$ was 0.7066 . The correlation coefficient of plastic recycling with $\mathrm{R} \& \mathrm{D}$ investments was 0.5166 . The correlation coefficient of total waste processing with $\mathrm{R} \& \mathrm{D}$ investments was 0.6519 .

Table 3. Correlation coefficient for individual indicators of waste management.

\begin{tabular}{|l|l|l|l|l|l|}
\hline & GDP & $\begin{array}{l}\text { Invest } \\
\text { ment } \\
\text { in } \\
\text { R\&D }\end{array}$ & $\begin{array}{l}\text { Labor } \\
\text { Productiv } \\
\text { ity in the } \\
\text { economy }\end{array}$ & $\begin{array}{l}\text { Human } \\
\text { Capital } \\
\text { Index }\end{array}$ & $\begin{array}{l}\text { Area } \\
\text { of the } \\
\text { count } \\
\text { ry }\end{array}$ \\
\hline $\begin{array}{l}\text { \% of } \\
\text { plastic } \\
\text { recycli } \\
\text { ng }\end{array}$ & 0.260 & 0.517 & 0.070 & 0.282 & - \\
\hline $\begin{array}{l}\text { \% of } \\
\text { waste } \\
\text { recycli } \\
\text { ng }\end{array}$ & 0.284 & 0.652 & -0.170 & 0.759 & 0.233 \\
\hline $\begin{array}{l}\text { \% of } \\
\text { recycli } \\
\text { ng }\end{array}$ & 0.435 & 0.707 & -0.012 & 0.714 & 0.453 \\
\hline
\end{tabular}

The obtained indicators confirmed the hypothesis that waste recycling is a science-intensive process that requires the development of the necessary research and technological base for the introduction of innovative technologies for recycling plastics and other products. The results of the analysis of the relationship between the human capital index and the depth of waste processing are also interesting. The higher the human capital index in a country, the higher the percentage of waste recycling, including both incineration and recycling (c-t 0.7588). However, the human capital index has no significant relationship with the level of development of plastic recycling in the country (c-t 0.2824). The lack of a close relationship with the production of countries ' GDP is explained by the high share of value added in non-manufacturing industries. Also, the hypothesis of the relationship of the country's territory with the development of environmental policy was not confirmed. Thus, the analysis suggests that the effectiveness of the country's environmental policy is determined by investments in the social sphere, the indicator of which is the human capital index and investments in R\&D. These indicators are closely related to all three indicators of the effectiveness of waste management and recycling of plastics.

\section{Discussion}

According to the results of the study, it was found that the problem of recycling polymer waste is currently acute all over the world, discussed and solved. Secondary polymers are not easy to sort when collecting garbage, but putting them into landfills is not a solution. Plastics decompose very slowly, retain their original qualities for a long time. This fact serves as a reason to consider the used plastic as a secondary raw material for the main polymer production. Thus, polymer recycling comes to the fore when considering the disposal of waste raw materials. The use of recycled plastic waste is extremely attractive for processors in terms of the cost of secondary raw materials.

Manufacturers in the plastics market are able to reduce raw material costs by up to $25 \%$ using recycled plastic materials. This reduces the dependence on natural raw materials, such as gas or oil. Polymer waste has properties that differ little from primary plastic. At the same time, there is less pollution to the environment than the production of base polymers from natural raw materials. For all indicators, recycling plastics has only positive impacts.

However, the prospect of processing plastics and getting a new product from it is very relevant and is supported and implemented in many countries. This may lead to reduced demand in the polymer market. Recycling is able to "squeeze" the demand for primary polyethylene, which is produced by large chemical companies. So, one of the main types of PET polymers is used for the production of bottles, production of fabrics, for sewing clothes. Its processing is developing all over the world, including in Russia. Therefore, analysts predict a decrease in demand for basic thermoplastics, which include polyethylene, polypropylene, polystyrene and polyethylene terephthalate. As can be seen from the data in Fig. 6 in Europe, the demand for recycled materials as a replacement for primary raw materials is increasing [15]. 


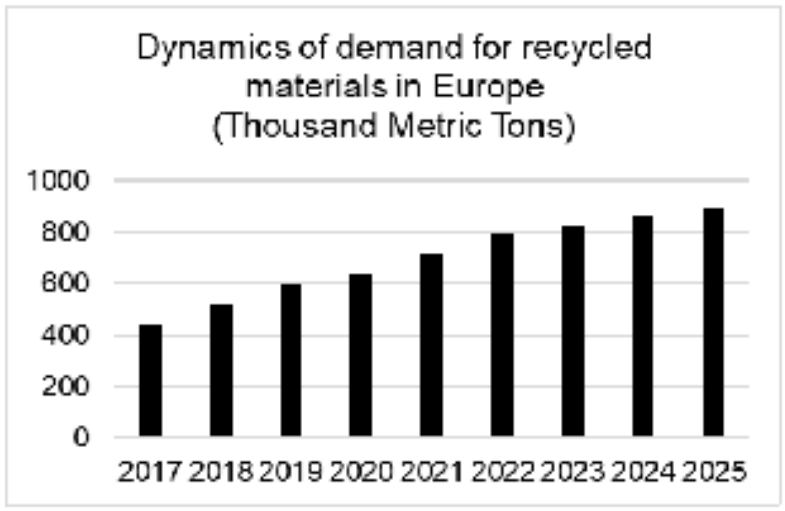

Fig. 6. Dynamics of demand for recycled materials in Europe.

Basic thermoplastics will also be affected by a reduction in demand-the rejection of disposable plastic utensils and plastic bags. However, the range of polymer products produced is very wide and it involves the use of composite materials, copolymers, etc. In this aspect, we predict the development of a new industry in the chemical industry of chemical recycling of polymers. Chemical recycling of plastics to base monomers will significantly reduce the cost of raw materials for companies producing polymer products and will contribute to a real reduction in the environmental burden.

\section{Summary}

Summing up the results of this review of the current situation in the polymer industry with recycling of polymer waste, it should be concluded that the prospects for this production are quite broad. In Russia, it is necessary to expand work towards the introduction of a circular economy. To create a working system, we need appropriate tax incentives from the state for the population, producers and processors. Recycling of polymers can significantly reduce the raw material costs of enterprises, and become a good, inexpensive, alternative source of production of products from basic polymers. The successful experience of the EU countries in the development of the circular economy once again proves the need to increase attention to the issue of industrial high-tech recycling of polymers, which allows us to consider plastics not as a threat to the planet, but as an effective environmentally friendly material.

\section{References}

[1] Statistical Yearbook of Russia, 1914, Petrograd, Publication of The Central Statistical Committee, 58 (1916).

[2] X. Li, T.-C. Ling, Mo K. Hung, Functions and impacts of plastic/rubber wastes as eco-friendly aggregate in concrete, Construction and Building Materials, A review, 240, 117869 (2020).

[3] I. Ignatyev, B. Thielemans, B. Vanderbeke, Recycling of Polymers, A Review [Electronic resource]. Available at: https://www.researchgate.
net/publication/262151364_Recycling_of_Polyme rs_A_Review.

[4] Ad $\bar{d}$ vanced Materials Research, 8th International Conference on Waste Management and Technology, Shanghai, China, 878, 23, 102769 (2014).

[5] The plastic waste crisis is an opportunity for the US to get serious about recycling at home [Electronic resource]. Available at: https://theconversation.com/the-plastic-wastecrisis-is-an-opportunity-for-the-us-to-get-seriousabout-recycling-at-home-93254.

[6] S. Chen, Z. Liu, S. Jiang, H. Hou, Carbonization: A feasible route for reutilization of plastic wastes, Science of the Total Environment, 710, 136250 (2020).

[7] D.Á. Simon, D. Pirityi, P. Tamás-Bényei, T. Bárány, Microwave devulcanization of ground tire rubber and applicability in SBR compounds, Journal of Applied Polymer Science, 137, 6, №48351 (2020).

[8] E. Clark, M. Bleszynski, F. Valdez, M. Kumosa, Recycling carbon and glass fiber polymer matrix composite waste into cementitious materials, Resources, Conservation and Recycling, 155, 104659 (2020).

[9] Y. Liu, C. Zhou, F. Li, H. Liu, J. Yang, Stocks and flows of polyvinyl chloride (PVC) in China: 1980-2050, Resources, Conservation and Recycling, 154, 104584 (2020).

[10] Toward a circular economy: Tackling the plastics recycling problem [Electronic resource].

Available at: https://theconversation.com/towarda-circular-economy-tackling-the-plasticsrecycling-problem-105546.

[11] Polymer recycling [Electronic resource]. Available at: http://magazine.sibur.ru/export/ ?url $=\% 2$ Fru $\% 2$ Farticle $\% 2$ Ffocus $\% 2$ Fpolymerrecycling $\% 2 \mathrm{~F} \% 3 \mathrm{Fpdf} \% 3 \mathrm{DY}$.

[12] Statistical collection, Industry in Russia 2019, M: Rosstat (2019) [Electronic resource]. Available at: www.gks.ru.

[13] Eurostat database [Electronic resource]. Available at: https://ec.europa.eu/Eurostat/.

[14] L. Ogrel, Polymer materials, Russian market of polymer materials and products from them: state and prospects, 2, 47-51 (2019).

[15] Materials obtained from the presentation of the international conference HIS, Markit Customer Care, Dusseldorf (18.10.2019). 